\title{
Neural excitability after paradoxical sleep deprivation: A replication and further examination
}

\author{
MARK J. HANDWERKER and WILLIAM FISHBEIN \\ The City College of The City University of New York, New York, New York 10031
}

\begin{abstract}
Mice that are deprived of paradoxical sleep (PS) for 3 days and given electroconvulsive shock (ECS) at one of several intervals after PS deprivation, display a reduction in brain-seizure thresholds. Brain-seizure thresholds are invariant in comparable groups of animals that are not deprived of PS. A shortening of the tonic phase of the convulsion is also observed in the PS-deprived animals; these findings suggest that PS-deprived animals receiving compensatory brain stimulation undergo a less severe convulsion. The experimental findings are interpreted to suggest that PS deprivation produces a central-neural change, during which time the brain is much more susceptible to agents that produce
\end{abstract}

We have recently produced data showing that electroconvulsive shock (ECS) administered systematically to mice after paradoxical sleep deprivation (PSD), produces memory disruption (retrograde amnesia) by either: (1) interfering with the maintenance of memory (Fishbein, 1971; Fishbein, McGaugh, \& Swarz, 1971 and confirmed by Wolfowitz and Holdstock, 1971, in the rat), or by (2) prolonging the fixation phase of the memory-consolidation gradient (Fishbein, 1972). In effect, it appears that PSD prolongs the time that ECS is an effective amnesic agent. Moreover, our findings suggest that the experimental approach of using the synergistic effects of PSD and ECS, rather than PSD alone, is a very fruitful way of uncovering the relationship between PS and memory.

Since the underlying biological bases of the synergistic memory-disturbing effects of the PSD + ECS treatment remains unclear, the present experiment was undertaken for the purpose of examining: (1) whether a central-neural change can be detected by the treatment, and (2) the time course of the change, if such a change exists. We imagined that an examination of brain neuroexcitability thresholds might provide at least one measure of the effects that the PSD + ECS treatment has on brain function; the present paper reports on the changes we have observed.

\section{METHOD}

\section{Subjects}

The subjects are $128 \mathrm{~F}_{2}$ mice, 60-70 days old, derived from DBA/2J and C57BL/6J strains, obtained from our laboratory's breeding stock.

\section{Apparatus}

A Lafayette A615B constant-current shocker is used to induce

This research was supported in part by CUNY Faculty Research Award Program Grant 1370, by NIMH Grant MH 24912, and by NSF Research Fellowship (U. S./France Exchange of Scientists Program) to William Fishbein. Mark J. Handwerker is now at Department of Psychobiology, University of California, Irvine. (transcorneal) convulsions in the mice. The durations of the various phases of the seizure are recorded to the nearest $1 / 10 \mathrm{sec}$ by two timers. The first is manually activated at the onset of stimulation and deactivated with the activation of the second timer. These timers measure the clonic and tonic phases of the seizure, respectively.

The experimental animals are deprived of PS by placing them on pedestals $3 \mathrm{~cm}$ in diam and $4 \mathrm{~cm}$ above the floor of the cage. The cage is filled with water $\left(22^{\circ} \mathrm{C}\right)$ to a level just below the top of the pedestal. Food and water are available ad lib. For hygienic reasons, the water-filled cages are replaced with fresh water once each day. The efficiency of this PSD method has been described elsewhere (Fishbein, 1971; Fishbein et al., 1971; Morden, Mitchell, \& Dement, 1967). The technique selectively deprives animals of $80 \%$ of PS while reducing total sleep time by only $11 \%$. This has been shown by monitoring sleep-wakefulness patterns by electroencephalographic and electromyographic recordings of chronically implanted animals.

\section{Procedure}

Each experimental animal is assigned a control of the same age and sex, which has occupied the same cage since weaning at 21 days. The controls are isolated during the PSD phase of the experiment in cages with wood shavings. Food and water are also available to these animals ad lib.

Following termination of 3 days $(72 \mathrm{~h})$ of PSD, the subjects are placed in cages with wood shavings. Each experimental (E) and control (C) are randomly assigned to one of four ECS treatments: $15 \mathrm{~min}\left(\mathrm{E}_{15}, \mathrm{C}_{15}\right), 30 \mathrm{~min}\left(\mathrm{E}_{30}, \mathrm{C}_{30}\right), 1 \mathrm{~h}\left(\mathrm{E}_{1}\right.$, $\left.\mathrm{C}_{1}\right), 3 \mathrm{~h}\left(\mathrm{E}_{3}, \mathrm{C}_{3}\right)$. The $\mathrm{C}_{15}, \mathrm{C}_{30}, \mathrm{C}_{1}$, and $\mathrm{C}_{3}$ groups are included to control for the time after $72 \mathrm{~h}$ of PSD when ECS is administered. The first transcorneal ECS $-7.5 \mathrm{~mA}$, root mean square (rms), $200 \mathrm{msec}-$ is applied at the times indicated above, according to the method described by Schwartzbaum, Hunt, Davies, \& Kimeldorf (1958). If the subject does not undergo a full clonic-tonic convulsion, it is returned to a wood-shavings cage and allowed $30 \mathrm{~min}$ rest before a second shock is delivered at $8.0 \mathrm{~mA} \mathrm{(rms)}$ for $200 \mathrm{msec}$. The intensity of stimulation is increased at increments of $.5 \mathrm{~mA}$ every $1 / 2 \mathrm{~h}$ until the animal convulses. The intensity at which each animal undergoes seizures comprises the convulsive threshold (CT) for that subject. Since Essig and Flanery (1966) have reported compounding effects resulting from sequential administration of ECS, leading to an increase in CT, any subject that does not convulse with $9.0 \mathrm{~mA}$ intensity is assigned a CT of $9.5 \mathrm{~mA}$; this occurs in 7 of $64(11 \%)$ experimental animals, and in 15 of 64 (23\%) controls.

The durations of the clonic and tonic phases of the behavioral 


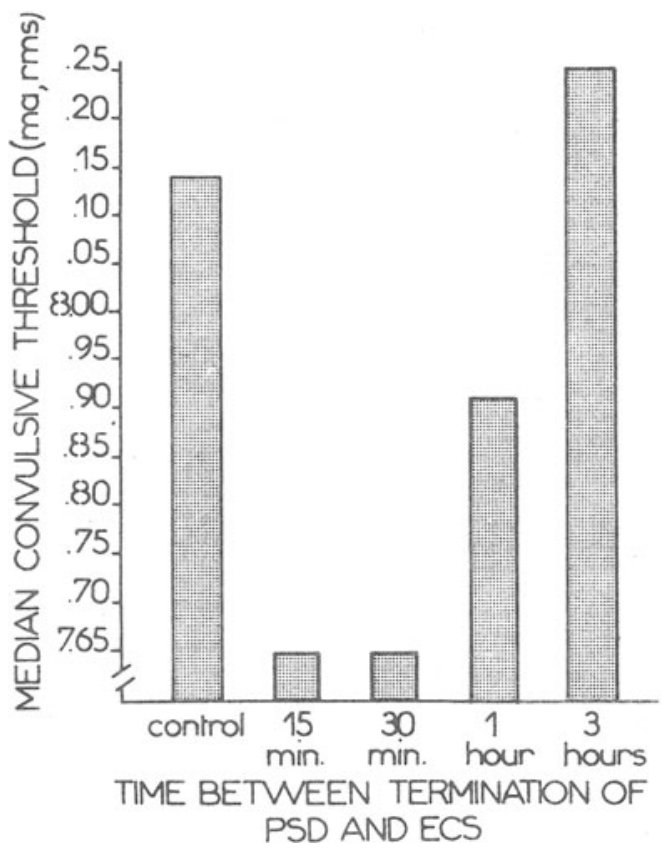

Figure 1. The effect of 3 days of paradoxical sleep deprivation (PSD) on electroconvulsive shock (ECS)-induced convulsive seizures. Each bar represents the convulsive threshold for separate groups of subjects administered ECS stimulation at various times after termination of PSD (or control).

seizure for each subject is recorded as the animal undergoes the convulsion. The clonic phase of the convulsion is observed to be very rapid and invariant in its duration. The tonic phase of the convulsion begins with the rapid onset of full extension of the body, head, and limbs, and the phase ends with the onset of body relaxation (postictal depression).

\section{RESULTS}

\section{Convulsion Thresholds}

Since there may be some doubt whether the convulsion raw-score data meet all the underlying assumptions of parametric tests, we decided to use more conservative (rank order) nonparametric tests.

The Kruskal-Wallis one-way analysis of variance, corrected for ties, reveals no significant difference between any of the control groups $\left(\mathrm{C}_{15}, \mathrm{C}_{30}, \mathrm{C}_{1}, \mathrm{C}_{3}\right)$ $(\mathrm{H}=2.93, \mathrm{df}=3)$; these groups are therefore pooled, and the pooled data are used for all subsequent paired comparisons. The Kruskal-Wallis test, however, does reveal a significant variation between the experimental groups $\left(E_{15}, E_{30}, E_{1}, E_{3}\right)(H=11.81, d f=3, p<.01)$. Detailed analyses by Mann-Whitney $U$ paired comparisons discloses significant differences between the pooled control group and $E_{15}$ and $E_{30}$ groups (large sample comparisons, $\mathrm{z}=1.82, \mathrm{p}<.05 ; \mathrm{z}=2.30$, $\mathrm{p}<.01)$. The $E_{1}$ group, although it does not reach statistical rejection level, is, however, in the same direction as the previous two groups $(\mathrm{z}=.98, \mathrm{p}<.16)$.
No difference is discerned in the 3 - $\mathrm{h}$ group.$(\mathrm{z}=.11)$ (Figure 1). Therefore, within the first hour after the termination of PSD, the experimental groups $\mathrm{E}_{\mathbf{1 5}}, \mathrm{E}_{\mathbf{3 0}}$, and perhaps the $E_{1}$ group, have significantly lower convulsive thresholds.

\section{Duration of the Tonic Phase}

In addition to the analyses conducted on CT, the duration of the tonic phase was also examined. These data meet all the assumptions of parametric tests. A 2 by 4 fixed-effects analysis of variance reveals a significant difference between the experimental and control groups $(\mathrm{F}=6.90, \mathrm{df}=1 / 94, \mathrm{p}<.01)$. One-way analysis of variance across the control groups $\left(\mathrm{C}_{15}, \mathrm{C}_{30}, \mathrm{C}_{1}, \mathrm{C}_{3}\right)$ indicates that they are regular and invariant $(\mathrm{F}=1.18$, $\mathrm{df}=3 / 41)$; these groups are therefore pooled, and the pooled data are used for all subsequent paired comparisons. One-way analysis of variance across experimental groups $\left(E_{15}, E_{30}, E_{1}, E_{3}\right)$, on the other hand, discloses a significant variation between these groups $(\mathrm{F}=2.99, \mathrm{df}=3 / 53, \mathrm{p}<.05)$. Further detailed analyses by Student's $t$ indicates significant differences between the pooled control group and $E_{15}, E_{30}$, and $\mathrm{E}_{1}$ groups (paired comparisons, $\mathrm{t}=3.51$, $\mathrm{df}=58$, $\mathrm{p}<.001 ; \mathrm{t}=1.99, \mathrm{df}=58, \mathrm{p}<.05 ; \mathrm{t}=2.00, \mathrm{df}=57$, $\mathrm{p}<.025$, all one-tailed). No difference can be discerned in the $3-\mathrm{h}$ group $(\mathrm{t}=-.33, \mathrm{df}=56) \quad$ (Figure 2). Therefore, in addition to the alteration of the CT, in the PSD animals, a decrease of the tonic phase of the convulsion is also observed; both CT and the duration of the tonic phase seem to be dependent upon the time

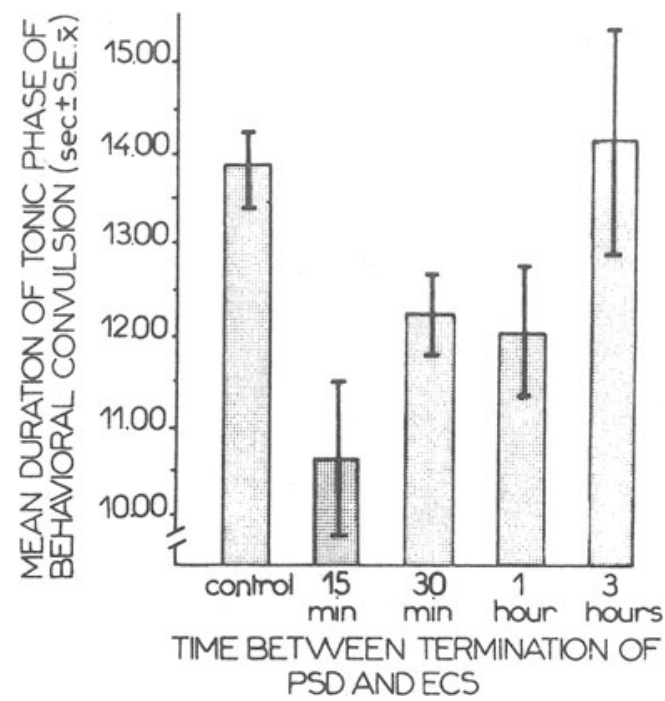

Figure 2. The effect of 3 days of paradoxical sleep deprivation (PSD) on electroconvulsive shock (ECS)-induced convulsive seizures. Each bar represents the duration of the tonic phase of the seizure for separate groups of subjects administered ECS stimulation at various times after termination of PSD (or control). 
between termination of PS and administration of ECS.

\section{DISCUSSION}

\section{PSD Or Restricted Activity}

One may wonder whether the experimental results are due to PSD or 3 days of restricted activity. Indeed, we have been very concerned with this question, and in previous studies (Fishbein, 1971; Fishbein et al., 1971) we have used restricted controls, i.e., animals placed on large pedestals. We found, however, that these animals are almost as deprived of PS as the experimental animals. We eventually abandoned the large pedestal controls, for in our view they lend no useful information to these experiments. Nevertheless, one would surely expect that if the activity of the animals had been severely restricted by the PSD procedure, a concomitant of this treatment would subsequently show up in some behavioral activity measure. For this reason, we were careful to observe the mice during the time they live on the pedestals in the midst of the pool of water. From what we observed, the animals do not appear to be severely restricted; rather, during the PSD procedure, the mice constantly climb, hang, and play about the wire-mesh tops of the cages. Be that as it may, we have systematically observed the open-field and first-trial passive avoidance activity [Fishbein (1970, 1971); Linden, Bern, \& Fishbein (in press)] of separate groups of $F_{2}$ mice (as well as other mouse strains) after PSD for as long as 7 days; we have found absolutely no change in activity when compared to non-PSD animals.

In sum, we think that it is highly unlikely that the minimal amount of activity restriction that the animals may undergo, if indeed there is any restriction at all, can account for the experimental results, particularly in light of the fact that there is now considerable evidence that the pedestal procedure produces selective deprivation of PS, with a variety of accompanying electrophysiological (Cohen \& Dement, 1965; Steiner \& Ellman, 1972), and neurochemical (Bowers, Hartmann, \& Freedman, 1966; Heiner, Godin, Mark, \& Mandel, 1968; Pujol, Mouret, \& Glowinsky, 1968; Karadzic \& Mrsulja, 1969) changes.

\section{Convulsion Threshold}

The experimental results indicate a significant reduction of the CT after PSD. These findings generally support the previous observations of Cohen and Dement (1965, 1970); Cohen, Duncan, and Dement (1970); Hartmann, Marcus, and Leinoff (1968); and Steiner and Ellman (1972). The level of brain stimulation necessary to elicit a convulsion is reduced as a result of PSD. We believe this is indicative of an increase in central-neural excitability. It is also clear that the neurally excited condition is temporary and diminishes rather quickly as a function of time following the end of the PSD.

It is indeed remarkable that following 3 days of PSD, which is known to produce a variety of changes in neurochemical levels (Bowers et al, 1966; Heiner et al., 1968; Karadzic \& Mrsulja, 1969; Pujol et al, 1968; Tsuchiya, Toru, \& Kobashi, 1969), the subjects recover within $3 \mathrm{~h}$ after treatment is terminated. Behaviorally, the animals are observed to sleep following the treatment. This is when the compensatory increase in the PS phase (PS rebound) occurs following experimentally induced periods of deprivation (Dement, 1965; Jouvet, Vimont, Delorme, \& Jouvet, 1964; Khazan \& Sawyer, 1963; Morden et al., 1967). It appears that the nervous system loses no time in replacing those lost materials necessary for homeostasis.

\section{Duration of the Tonic Phase}

It is of interest to clarify, what might seem at first, findings that are contradictory to the observations of Cohen and Dement (1970). While these investigators report a prolongation of the tonic phase of the convulsion as a result of PSD, we find a shortening of the phase. In their experiment, however, the animals are convulsed once, at a level well above CT $(8 \mathrm{~mA}$, $400 \mathrm{msec}$ ). Since these investigators were not studying $\mathrm{CT}$, the duration of the ECS was twice the duration used in our experiment. In the course of obtaining CT, we exposed the animals to several ECS stimulations. The shorter tonic phase, therefore, might possibly be the function of one of two possible events (or both), which, unfortunately, we cannot clearly separate with the present experimental design. The first reason for the decrease in the tonic phase might be that the PSD animals receive fewer ECS stimulations (because they convulse with a lower-level ECS current), than the control animals, suggesting a possible functional relationship between current intensity and duration of the tonic phase. The second possibility might be the compounding effect of several electrical stimulations, before the convulsion is actually produced. In this vein, it is interesting to comment on the salient observations of Cohen, Duncan, and Dement (1967) and Steiner and Ellman (1972), who report that compensatory PS rebound is diminished in cats and rats, respectively, who receive brain stimulation prior to recovery. They interpret their findings to suggest that brain stimulation compensates for the loss of PS time. From our point of view, PS loss may be expressed in terms of prolonging the tonic phase. Thus, it may be possible to infer that the decreased need for PS during recovery, as a result of compensatory ECS stimulation, might also be manifest in terms of the tonic phase. Hence, an animal requiring a full complement of PS rebound as a result of deprivation, will undergo a prolonged tonic convulsion, as observed by Cohen and Dement (1970). On the other hand, an animal receiving compensatory brain stimulation as is the case in this experiment, will undergo a less severe tonic convulsion. We will have to 
pursue this problem further before we can say with any certainty that our findings lend support to those of Cohen and Dement (1970) and Steiner and Ellman (1972).

\section{Neural Excitability and Amnesia}

Cohen and Dement (1965, 1970); Cohen et al. (1967); Cohen, Thomas, and Dement (1970); Hartmann et al. (1968); and Steiner and Ellman (1972) have all attributed PSD-produced increase in neural excitability to alterations in brain catecholamine levels. In another report (Linden et al., in press) we also suggest that memory disruption produced in PSD animals given ECS, may be the result of an unspecified change in catecholamine metabolism. In our previous experiments, we have, however, also proffered the alternative possibility that PSD may render ECS a "more effective amnesic agent" (Fishbein et al., 1971), for such an interpretation was tenable, too. The present experiment makes it very clear that a central-neural change occurs within the brains of PSD subjects. There is now considerable evidence that electrical brain stimulation affects a variety of systems and structures in the central nervous system (see Kesner \& Wilburn, 1974 for one possible review of this literature), and it is our view that PS influences these systems to a considerable extent. In our previous reports, as in the present experiment, the time after the end of PSD (when ECS is administered) is the main independent variable-when those systems related to sleep and perhaps memory mechanisms are recovering from PSD. In sum, the present experiment provides very strong evidence that PSD produces a central-neural change, during which time the brain is much more susceptible to agents that produce amnesia.

\section{REFERENCES}

Bowers, M. B., Hartmann, E. C., \& Freedman, D. X. Sleep deprivation and brain acetycholine. Science, 1966, 153, 1416-1417.

Cohen, H. B., \& Dement, W. C. Sleep: Changes in threshold of ECS in rat after deprivation of the "paradoxical" phase. Science, 1965, 150, 1318-1319.

Cohen, H. B., \& Dement, W. C. Prolonged tonic convulsion in REM deprived mice. Brain Research, 1970, 22, 421-422.

Cohen, H. B., Duncan II, R. F., \& Dement, W. C. Sleep: The effect of electroconvulsive shock in cats deprived of REM sleep. Science, 1967, 156, 1646-1648.

Cohen, H. B., Thomas, J., \& Dement, W. C. Sleep stages: REM deprivation and electroconvulsive threshold in the cat. Brain Research, 1970, 19, 317-321.

Dement, W. C. Recent studies in the biological role of rapid eye movement sleep. American Journal of Psychiatry, 1965, 122, 404-408.

Essig, C. F., \& Flanery, H. G. The importance of the convulsion in the occurrence and rate of development of electronconvulsive threshold elevation. Experimental Neurology, 1966, 14, 448-452.

Fishbein, W. Interference with conversion of memory from short-term to long-term storage by partial sleep deprivation. Communications in Behavioral Biology, 1970, 5, 171-175.

Fishbein, W. Disruptive effects of rapid eye movement sleep deprivation on long-term memory. Physiology and Behavior, $1971,6,279-282$.

Fishbein, W. Sleep deprivation: Total, partial and selective. In $M$. H. Chase (Ed.), The sleeping brain. Los Angeles: Brain Information Service/Brain Research Institute, 1972, 1, 347-355.

Fishbein, W. McGaugh, J. L., \& Swarz, J. R. Retrograde amnesia: Electroconvulsive shock effects after termination of rapid eye movement sleep deprivation. Science, 1971, 172, 80-82.

Hartmann, E., Marcus, J., \& Leinoff, A. The sleep-dream cycle and convulsive threshold. Psychonomic Science, 1968, 13, 141-142.

Heiner, L. Godin, Y., Mark, J., \& Mandel, P. Electroly te content in brain and blood after deprivation of the paradoxical phase. Journal of Neurochemistry, 1968, 15, 150-151.

Jouvet, D., Vimont, P., Delorme, F., \& Jouvet, M. Etude de la privation selective de la phase paradoxale de sommeil chez le chat. Comptes Rendus des Seances do la Societé de Biologie (Paris), 1964, 158, 756-759.

Karadizic, V., \& Mrsulja, B. Deprivation of paradoxical sleep and brain gly cogen. Journal of Neurochemistry, 1969, 16, 29-34.

Kesner, R. P., \& Wilburn, M. W. A review of electrical stimulation of the brain in context of learning and retention. Behavioral Biology, 1974, 10, 259-293.

Khazan, N., \& Sawyer, C. "Rebound" recovery from deprivation of paradoxical sleep in the rabbit. Proceedings of the Society of Experimental Biology and Medicine, 1963, 114, 536-539.

Linden, E. R., Bern, D., \& Fishbein, W. Retrograde amnesia: Prolonging the fixation phase of memory consolidation by paradoxical sleep deprivation. Physiology and Behavior, in press.

Morden, B. Mitchell, G, \& Dement, W. Selective REM sleep deprivation and compensation in the rat. Brain Research, $1967,5,339-349$.

Pujol, J. F., Mouret, J., \& Glowinsky, J. Increased turnover of cerebral norepinephrine during rebound of paradoxical sleep in the rat. Science, $1968,159,112-114$.

Schwartzbaum, J. Hunt, E., Davies, \& Kimeldorf, D. The effect of whole body $X$ irradiation on the electroconvulsive threshold in the rat. Journal of Comparative and Physiological Psychology, 1958, 51, 181-184.

Steiner, S. S., \& Ellman, S. J. Relation between REM sleep and intracranial self-stimulation. Science, 1972, 177, 1122-1124.

Tsuchiya, K., Toru, M., \& Kobashi, T. Sleep deprivation. Changes of monoamines and acetylcholine in rat brain. Life Sciences, 1969, 8, 867-873.

Wolfowitz, B. E., \& Holdstock, T. L. Paradoxical sleep deprivation and memory in rats. Communications in Behavioral Biology, 1971, 6, 281-284.

(Received for publication July 16,1974 ; revision received November $14,1974$. ) 